\title{
Being and Performing "Older" Woman in Electronic Dance Movement Culture

\author{
Feature ARticle $\longrightarrow$
}

Alice O'Grady and AnNa Madill

UNIVERSITY OF LEEDS (UK)

\begin{abstract}
This article foregrounds the accounts of a cohort of clubbers who are largely ignored both by journalists and scholars alike. Grounded in the accounts of aging female clubbers and their participation in electronic dance music culture, it investigates the lived experience of being and performing the category of "older woman" in this context. It examines the materiality of their participation and their tactical responses to being in an environment that has been associated traditionally with youth. In a landscape where scholarship on female participation in club cultures is, at best, scarce, research into the experiences of older women in dance music culture is virtually nonexistent. As such this article represents a first step in addressing a significant gap in understanding women's engagement with dance cultures as they mature.
\end{abstract}

KEYWORDS: aging, space/other-space, female experience, psytrance, well-being

Alice O'Grady is Professor in Applied Performance and Head of the School of Performance and Cultural Industries at the University of Leeds. Her research is concerned with open forms of participation, play and performance within a range of contexts. Her latest book, Risk, Participation and Performance Practice: Critical Vulnerabilities in a Precarious World, was published by Palgrave in 2017. Email: <a..ogrady@leeds.ac.uk>. Website: $<\underline{\text { https://leeds.academia.edu/AliceOGrady }>}$

AnNa Madill is Professor in Qualitative Inquiry and Deputy Head of the School of Psychology at the University of Leeds. Her research focuses on gender/sexuality, well-being and the resilience of people considered to be vulnerable.

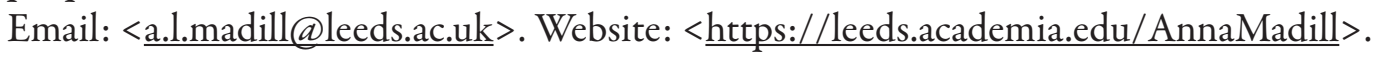

Dancecult: Journal of Electronic Dance Music Culture 11(1): 7-29

ISSN 1947-5403 @2019 Dancecult http://dj.dancecult.net

http://dx.doi.org/10.12801/1947-5403.2019.11.01.02

desncecult 
A survey called "The Great Indoors" conducted by Currys PC World, a British electrical retailer, concluded that technological advances in home entertainment mean that Britons are "hang(ing) up their dancing shoes and prefer staying in to going out on the town" (Dixons 2017). According to its results, 31 is the average age that people prefer staying at home and that by the age of 37 adults are too old to be dancing in nightclubs. Over a third of its respondents considered it "tragic" to see people in their 30s and 40s in nightclubs. In the same vein, an article in The Telegraph (Morris 2014) asks the question, "how old is too old to go clubbing?" The piece was written after Usain Bolt was spotted at a London nightclub at the age of 27. As purveyors of televisions, laptops and computer games it is unsurprising that businesses such as Currys might want us to believe that engaging with club culture has a shelf life. Querying Bolt's participation in club culture, however, is more likely a comment on incongruity rather than age. There is a mismatch between the public's expectations of a highly trained athlete and its view of what constitutes "appropriate" behaviour and yet press reports honed in on Bolt's age as being the factor that warranted the headline.

These two examples give brief insight into the preconceptions and prejudices surrounding age, identity and participation in club cultures that infuse the popular press and yet they do not take into account the additional marker of gender that is the focus of our article. Here we consider accounts of aging female clubbers and their participation in electronic dance music (EDM) culture to explore the lived experience of being and performing the category of "older woman" in this context. We examine the materiality of their participation and their tactical responses to being in an environment that has been associated traditionally with youth. In a landscape where scholarship on female participation in club cultures is, at best, scarce, research into the experiences of older women in dance music culture is virtually non-existent. As such this article represents a first step in addressing a significant gap in understanding women's engagement with dance cultures as they mature.

According to market researchers Mintel, the UK nightclub market is in serious decline with nearly half of the country's night clubs shutting in the past ten years (McGrath 2016). Attendance figures have dropped so dramatically that the Office for National Statistics no longer considers participation in club culture as being statistically significant and has stopped reporting on it. Mintel say the group of people most likely to leave clubbing behind are the over 25s (Davies 2013). Despite this rather bleak picture, there are pockets of resistance against the broader trends which provide the locus of study for this article. Although a relatively "clandestine phenomenon" within the UK, psytrance has a global following with a thriving transnational network of festivals such as Boom (Portugal), Ozora (Hungary), Rainbow Serpent (Australia), Hill Top (India) and Origin (South Africa) that attracts thousands of participants annually (Lindop 2010: 119). In the UK, the scene is associated with "alternative" festival culture and, as Lindop argues, has a strong "freak" aesthetic that brings together the young and the old, a mixture of free festival veterans and newer converts (2010: 126). "Veteran insiders" play a vital role in the reproduction of psytrance scenes internationally, and it is not uncommon to see people in their 60 s and 70 s partying next to 
people in their 20s (D'Andrea 2010: 48). As a result, the psytrance community is generally considered to be inclusive, tolerant and intergenerational. These attributes, however, are themselves worthy of interrogation and critique and, as our later analysis will bear out, our research problematises psytrance's narrative of inclusivity in that our participants did, indeed, face ageism and sexual harassment. Despite its wide demographic, the psytrance scene still presents a challenge for older women who select this terrain as their club of choice. ${ }^{1}$ Our research sets out to ask how participants navigate this landscape as older women. What does it offer them that other contexts do not? What drives their participation and what strategies do they adopt to manage the responses their participation provokes?

\section{Literature AND the Discourse of AbSence}

Psytrance has its roots in 1980's Goa which is a well documented moment in EDM cultural history (St John 2010, 2012). The values of PLUR (Peace, Love, Unity and Respect) seeded here were transported to the British rave scene and have, over time, been woven into the fabric of psytrance parties across the world. With more than a passing nod to the hippie trail that fuelled the emergence of Goa trance over 30 years ago, the world of psytrance offers participants the opportunity to extend their clubbing practice well into middle age and beyond.

The psytrance scene has a provenance that spans decades and is strangely resistant to change not only in terms of its musical terrain but also in the striking visual aesthetic that accompanies it. The psychedelic decor, clothing, art work all resonate with 1960's sensibilities and people born in that decade continue to access this peculiarly changeresistant cultural seam. Although not limited to psytrance, the phenomenon of an aging dance floor is particularly noticeable in this context and provides a useful setting for an investigation into how constructions of identity are played out within the frame of EDM culture. Older people are regularly engaging in a practice that has traditionally been seen as the preserve of the young and are showing no signs of stopping. This not only leads to some interesting questions about the nature of EDM as an aging cultural product but also signals a shift in the way society views age appropriate behaviours in general. When our attention turns to older women and their clubbing practice, further questions emerge about the appropriateness of certain behaviours that challenge conventional attitudes to both gender and age in tandem.

Remarkably little is written about the particular experiences of female clubbers (with the exceptions of Henderson 1993; McRobbie 1993; Pini 1997; Hinchliff 2001; Measham 2002), even less so about the experiences of older female clubbers. Maria Pini's work, Club Cultures and Female Subjectivity, is one of the first sustained explorations of the modes of femininity being lived, figured and constituted within club contexts. It examines what participation in club culture offers women who are seeking to move beyond the constraints of traditional social roles associated with being a woman, such as wife, mother and care giver 
(Pini 2001: 1-2). Couched in largely utopian terms, a register which was not uncommon for the literature of the time, Pini explores the "elsewheres" afforded by rave culture and the sense of belongingness that accompanies the emerging narratives. Pini's research began in the early 1990s when the phenomenon of rave culture was still in its relative infancy. However, Pini is at pains to point out that her work is not a youth cultural study as her informants range between the ages of 19 and 35. Part of the significance of Pini's study is that it investigates the recreational practices of women who have traditionally been thought of in relation to the domestic context. Seventeen years on from Pini's findings and a full 25 years on from when she began her research, the scene and the women in it have grown older and yet their narratives are noticeable by their absence from extant scholarship. Our own investigation seeks to address that gap by placing the voices of older female clubbers at the heart of our analysis and, at the same time, challenging and critiquing the issue of invisibility both within the practice of clubbing and the practice of writing about clubbing.

The other notable work on the experience of female clubbers is Fiona Hutton's Risky Pleasures? Club Cultures and Feminine Identities. Published in 2006, her introduction repeats the scarcity refrain and begins by identifying the "lack of space given to the discussion of female clubbers" within scholarly literature (2006: 1). Her approach attempts to foreground women's stories but also seeks to surface the complex debates around risk, pleasure, drug use and sex in relation to societal attitudes about femininity. Using qualitative, ethnographic methods that prioritise the voices of participants Hutton, like Pini, points out that clubbing as a leisure activity "does not appeal solely to young people" (Hutton 2006: 3). Her informants range from 21 to 39 and, as such, the sample is relatively broad. However, much of the discourse focusses on attitudes to risk-taking in terms of the experiences of "young women" and this is a repeated phrase throughout. Age is not a central concern and is barely mentioned as a factor that influences the construction of female subjectivity. Nevertheless Hutton pursues some pertinent questions that could quite easily be (re)appropriated to incorporate the very particular experience of women in their middle age and beyond. Imagine the following being applied to a consideration of clubbers over 50 :

[d] o female clubbers feel that they can challenge stereotypes of femininity and sexuality within club spaces; can they experiment with drugs and sex, push the boundaries of femininity without being censored or punished for their behaviour/s? Or do . . - women feel constrained and pressurised into having casual sexual encounters and acting out 'acceptable' femininities? (Hutton 2006: 5)

If we shift the focus of this passage, only slightly, to older women, it is possible to see how differently we might answer these questions and begin to shed new light not only on the experiences of the women involved but the wider socio-cultural frameworks within which they live. Although early club cultural scholarship tended to focus on the experiences of heteronormative men and of youth more broadly (e.g. Redhead 1993, Bennett 1999; Chatterton and Hollands 2003), more recent research has explored dance-based activities 
of individuals who do not perform their age in accordance with heteronormative social convention, preferring instead to occupy "queer temporalities" in which "being in the present takes precedent over a reproductive future" (Taylor 2010:904). With a similar interest in how alternative temporalities are constructed and inhabited, our own study explores the experiences and elsewheres of women in their 50s and 60s who continue to participate in club cultures as a way of accessing an alternative social modelling of living as an older woman in a society obsessed with holding back the aging process.

While club cultural criticism of the late 1990s/early noughties was dominated by male authors (with a few notable exceptions like Rietveld, McRobbie, Thornton and Pini), this imbalance is being addressed by writers such as Tami Gadir $(2016,2017)$, Rebekah Farrugia (2004, 2012), Maren Hancock (2017), Magdelena Olszanowksi (2012) and Tara Rodgers (2010). However, the focus of this later work tends to be on DJ culture and women's contribution to, or position within, the night time economy rather than participant experience which, for older women at least, remains unexplored.

A recent special edition of Dancecult sought to highlight the centrality of the contribution of women to the cultural production of EDM culture while at the same time interrogating the latent misogyny prevalent in the scene. The editors critique the way in which discourse around female participation in DJ culture is often couched in terms of "lack" or absence. They argue, "[c] onstantly focussing on a lack is an affront to the women who form the scene and have developed it throughout its history" (Farrugia and Olszanowksi 2017: 2). They seek to address the problem by dedicating a special issue that re-writes the limited histories that have hitherto focussed on men's contribution to the culture. Although the articles featured in the special issue concentrate on cultural production rather than consumption, the editors ask some useful questions that foreground the complexities of separating out the category of "women" in relation to a particular context.

What is particular to a woman's subjectivity, identity and experience in the scene? How are spaces for and by women produced and maintained?... How can we account for and present women's experiences without an obfuscation of each of their specificities? How can the seemingly problematic foregrounding of gender as a boundary marker be useful? (Farrugia and Olszanowksi 2017: 4)

The specificity of women's experience drives our own research agenda and these questions chime with our own investigation. However, while we acknowledge the problematics of using gender as a boundary marker, in the instance of participant experience, research indicates that both gender and age are influential factors in relation to women's active rave participation (Gregory 2009: 65). In her article "Too Young to Drink, Too Old to Dance: The Influences of Age and Gender on (Non) Rave Participation", Julie Gregory considers age and gender as configurations of social discourse that determine how women enter, engage with and ultimately leave rave culture. Her investigation concludes that women are unable to imagine a "lasting adult femininity" within rave as the role of aging woman is seen 
as being incongruent with rave participation (2009: 75-6). If women's raving is associated with youth, freedom and experimentation, it is time limited and subject to the ever present power relations that operate in other spheres. As Gregory argues, "once outside-and oftentimes inside - the rave and related spaces, women have to contend with the social meanings attributed to their specifically aged, gendered, sexualised and drugged bodies" (2009: 76). For Gregory's interviewees this means stopping their involvement with rave culture when age and gendered responsibilities become barriers by virtue of what is seen to be appropriate.

While Gregory's article introduces the issue of gender and age in the context of clubbing, it focusses on the past experiences of women who have since given up raving and their reasons for doing so. While there is a general shift in the literature that challenges the marginalisation of women in relation to EDM production (see Farrugia 2012, Reitsamer 2012 or Farrugia and Olszanowksi 2017), age is still very much absent from the discourse and female aging entirely invisible. As Pini argues, much of the early literature on rave culture tends to eradicate distinctive identities with ravers being written about as essentially sexless, ageless and raceless. According to the post-modern view of social dance cultures, loss of self is the prize as one merges into the raving machine (Jordan 1995). In the rave identity disappears and meaning evaporates (Melechi 1993; Rietveld 1993). In contrast to this, we will argue that identity is the chief indicator of how and why older women continue to mobilise clubbing as a way of accessing the "elsewhere": in Rodgers' words "a space for mutual encounters between humans and technologies, between familiarity and otherness, that motivates wonder and a sense of possibility" (2012: 477). Hence, the research question guiding our study is: What is the experience of being and performing "older woman" in EDM culture?

\section{METHOD}

Ethical approval was granted by the Ethics Committee of the Faculty of Arts, Humanities and Cultures at the University of Leeds in which the study was conducted (PVAR 17-078, 21 February 2018). Signed informed consent was obtained from all participants to take part in the study, to audio-record interviews, and to use anonymised quotes in reports of the research.

\section{PARTICIPANTS}

Participants were recruited by word of mouth through the first author's personal networks. All four were white British women who identified as an older member of EDM culture with particular connection to the psytrance scene table 1. 


\begin{tabular}{|c|c|c|c|c|c|c|}
\hline Pseudonym & $\begin{array}{l}\text { Age } \\
\text { (yrs) }\end{array}$ & $\begin{array}{l}\text { Relational } \\
\text { status }\end{array}$ & Occupation & Interview context & $\begin{array}{l}\text { Interview } \\
\text { length } \\
(\mathrm{min} / \mathrm{sec})\end{array}$ & Engagement in EDM \\
\hline Anita & 52 & Married & Professional & $\begin{array}{c}\text { In private at } \\
\text { agreed location }\end{array}$ & 38.25 & $\begin{array}{l}\text { I've only really got into shall we say } \\
\text { the electronic dance scene in my later } \\
\text { years }\end{array}$ \\
\hline Bev & 57 & In relationship & Professional & $\begin{array}{c}\text { In private at } \\
\text { agreed location }\end{array}$ & 42.00 & $\begin{array}{l}\text { I didn't properly get back into it } \\
\text { until my late } 40 \text { s and then I met my } \\
\text { partner when I was } 50 \text { and I've never } \\
\text { looked back. That was when it- that } \\
\text { was when I engaged properly }\end{array}$ \\
\hline Carol & 67 & Married & Retired & $\begin{array}{l}\text { At home in } \\
\text { private }\end{array}$ & 41.20 & $\begin{array}{l}\text { I must've been in my 40s. Said that } \\
\text { he thought it would be a whole } \\
\text { different experience from anything } \\
\text { I'd ever you know had as a teenager } \\
\text { and he finally broke down my will } \\
\text { and I was absolutely converted }\end{array}$ \\
\hline Diane & 54 & Divorced & Homemaker & $\begin{array}{l}\text { At home with } \\
\text { family }\end{array}$ & 30.10 & $\begin{array}{l}\text { My ex-husband introduced me when } \\
\text { I was } 27 \text { into the psytrance scene }\end{array}$ \\
\hline
\end{tabular}

TABLE 1: DESCRIPTION OF PARTICIPANTS IN THE ORDER INTERVIEWED

\section{RESEARCHERS}

The first author is 48 years old with a long standing connection to EDM culture and the psytrance scene in particular, both as scholar and participant. She is an applied performance specialist with research interests in playful engagement with space, risk and participatory cultures. The second author is 53 years old and unfamiliar with EDM culture. She is an academic psychologist with expertise in qualitative methods of inquiry and research interest in gender, health and well-being.

\section{DATA Generation}

All participants took part in a face-to-face, one-to-one semi-structured interview during the spring of 2018 (Madill, 2012). The interview schedule was devised by the authors based on the first author's personal experiences, her knowledge of the field of inquiry, and the second author's experience of constructing fruitful open questions, probes, and follow-ups. Given that the schedule elicited rich and relevant material with the first participant, it was retained throughout the study. Interviews were conducted by the first author and lasted between 30 and 42 minutes. Audio-recordings were transcribed by a professional company with appropriate confidentiality procedures in place. Transcripts utilised orthographic conventions (like a playscript). Being mindful of the limitations of the scale, the researchers made a conscious decision to focus on the testimony of a small number of informants to facilitate close analysis of the data. There has been no attempt to generalise from the data gathered. Instead the article presents an abstracted discussion of the data and makes suggestions for further research as a result of taking these first steps into understanding the experiences of older women in this context. 


\section{DATA ANALYSIS}

Transcripts were analysed using thematic analysis (TA) as articulated by Braun and Clarke (2006). This exposition of TA is particularly useful because it allows researchers to modify their approach depending on their research question, unique data set and personal commitments to analytic paradigm through outlining four decisions shaping the analytical procedure.

\begin{tabular}{|c|c|c|c|c|}
\hline Decision & \multicolumn{2}{|c|}{ Dialectic } & Decision \\
\hline$\sqrt{ }$ & $\begin{array}{c}\text { Rich description of the data } \\
\text { set }\end{array}$ & vs. & $\begin{array}{c}\text { Detailed account of one particular } \\
\text { aspect of the data set }\end{array}$ & $\mathrm{x}$ \\
\hline$\sqrt{ }$ & Inductive analysis & vs. & Theoretical analysis & some \\
\hline$\sqrt{ }$ & Semantic themes & vs. & Latent themes & $\mathrm{x}$ \\
\hline$\sqrt{ }$ & Realist & vs. & Constructionist & $\mathrm{x}$ \\
\hline
\end{tabular}

TABLE 2: DECISIONS MADE ON TYPE OF THEMATIC ANALYSIS UNDERTAKEN

As outlined in table 2, we conducted an analysis that sought to capture a rich description of the data set, grounded bottom-up in the data, and focused on what our participants actually said as opposed to being particularly interpretative. This approach is situated in a realist epistemology in which we, without being naïve, chose to accept pretty much at face value our participants' accounts (Madill, 2008). After drafting an initial analysis, we noticed the potential fruitfulness of utilising some theoretical concepts to enhance our findings, specifically the Bakhtinian concept of "chronotope" which alerts the researcher to the ways in which participants evoke a constellation of "time-space" in their accounts (Morson 1994). Hence, this paper provides a predominantly inductive analysis and, where appropriate, draws also on these theoretical understandings of time-space confluence.

In terms of procedure, the second author outlined potential themes of interest relevant to addressing the research question: what is the experience of being and performing older woman in EDM culture? She did so through careful reading of the transcripts, writing notes in the margins, and cycling iteratively between the developing theme and reading the transcripts several times. The two authors then met to discuss the emergent themes. It was at this point that chronotope was identified as a potential useful concept for enhancing the analysis. The first author then spent some time reading the transcripts to provide additional analytical insights, to check that the developing analysis fitted the data well and adequately addressed the research question, and to provide additional analytical insights. These were conveyed to the second author who produced a more detailed draft analysis. The authors cycled through this process several times until both were satisfied with the quality of the written analysis. 


\section{ANALYSIS}

In the analysis that follows, we make the distinction between being and performing older woman as a way of understanding what it means to inhabit this position within the context of electronic dance music culture. The distinction is subtle but significant. Age is not simply a chronological marker of identity. It is something we accomplish or perform (Laz 2003). As West and Zimmerman argue, we "do age" just as we "do gender" (1987). Both are performances of the self rather than fixed, biological determinants. Calasanti and Slevin point out that within the structures and institutions that frame our world, we work to give meaning to our age (2006: 255). Our analysis attempts to reveal this process of "sensemaking" in order to reveal how age performs and is performed in the context of electronic dance music culture.

Two themes were considered important in understanding our participants' experience of performing and being an older woman in this context: visibility and other-space. Each theme is constituted by several sub-themes as explicated in the following analysis. Each subtheme is evidenced by quotations from the interviews and, where appropriate, we explore the ways in which our participants' experiences are situated in particular constellations of time-space.

\section{THEME 1: VISIBILITY}

Visibility captures the way in which, as older women, our participants experienced themselves as unusually conspicuous in EDM culture, the problems that this creates for them, and the strategies they have developed to manage these issues. Visibility is divided into three sub-themes: (non-)acceptance, appearance and sexual harassment.

\section{SUb-THEME 1: (NON-)ACCEPTANCE}

Our participants were recruited because their very engagement in EDM culture situates them in a particularly interesting time-space. That is, their chronological age positions them as an unusual participant in EDM space and all our participants recognise the potential, as least, of being considered out of place. For example, Diane states that "people are often amazed that somebody my age is still up there" but that "it's getting more and more acceptable now because the scene is aging. There's a lot more people aging on the scene with it". Anita suggests that "society doesn't recognise that older people still enjoy that scene" but that, as an older woman, within dance culture itself this is not such a problem and, in fact, it is "very nice to be recognised as someone that has, is having a positive experience in a club night and is drawn to what might be cool music". Interestingly, she contrasts this to the patronising and potentially misogynist "'grab a granny' sort of nights" of her youth. Carol, too, reports that she feels accepted as an older woman in the scene describing how young people say things like "oh I wish I could bring my mum." Diane, too, reports positively that "sometimes when we go out I get called 'rave mum" while, at the same time, noting the 
pleasure of being perceived, not as an older woman per se, but as a person: "they don't see age, they just see a person, in my experience. I could be wrong. Maybe other people have had different experiences but a lot of time people don't see the age".

These positive experiences, however, are contrasted to a background of resistance from younger people which spans annoying curiosity to outright hostility. For example, Carol describes how "you get some that look askance". Anita reports comments such as "'oh you're older than my mum' you know 'what're you doing here?'... you want people to leave you alone". And Bev explains how she has had to develop a strategy to deal with young people who are over-intrusive: "I had a great deal of fun with him. I quite often have a lot of fun. Sometimes I tell people I'm 75". However, as Diane recounts, it can be difficult not to have negative expectations: "I used to think that the younger ones would look at me and go 'oh go home' you know? 'Go home. You should be home knitting'” And this was contrasted with the way in which older men were treated. For example, Anita said: "I find if people come up to me in the same-in a positive way, they will enquire about my age and it - they don't enquire about [name of husband]'s age".

Older women often experience themselves becoming with age "invisible" in public spaces. As Germaine Greer explores this is a highly gendered phenomenon which is not inflicted on older men (2018). On the other hand, our participants felt increasingly visible or, more negatively, conspicuous in the dance scene. Bev comments on this specifically: "I probably am more visible but then I would-I think women of our age generally become less visible". Carol, too, reports how she feels:

more visible now because of my age and certainly the last time I went I drew so many more comments about my age. ... I think I feel more visible now with the increase in references to how old I am.

Anita tried to be positive, saying "you are more visible and it has a mixed-I don't think it's always negative. I think some people see it very very positively but not enough perhaps". However, she also experiences her increased visibility as a problem because "it can interfere with the enjoyment of the whole thing, I mean the concept of going out is all about being free".

It is interesting how, even when our participants' age brings them a certain status in the psytrance scene, they are implicitly situated in domestic and familial time-space. Hence, Diane, is respected as a "rave mum" but also abused and told to "Go home. You should be home knitting". Anita is told ambiguously, maybe, "you're older than my mum" and, similarly, young people tell Carol "I wish I could bring my mum". This gendered domestication is clocked by Anita who tries to make sense of it saying "I don't know if that's to do with mums. This concept of, you know, because we are-because we give birth we're thought of differently. I don't know. I don't know what it is but he doesn't get asked his age". 
SUb-THEME 2: AppeARANCE

The problematic aspects of participants' increased visibility seems related, in particular, to their physical appearance. For example, Bev explains that "I've been feeling sort of more vulnerable over the last year and just not quite myself. It's that I know I'm going to stand out in a club because I've got white hair", and Carol feels criticised sometimes about her outfits, saying "it shouldn't matter but it does matter to me if a young woman says to me 'oh you dress...". Hence, as older women, our participants could find themselves in a paradox as Bev explains: "I don't want to be invisible. I don't want to draw unnecessary attention to myself".

Given this experience of implicit and explicit judgement, getting ready for an evening out could be tinged with self-doubt about how to present themselves. For example, Anita explains that "it's that balance between wanting to look nice and feel nice and not wanting to look overdone and silly you know but wanting to perhaps, you know, look like you're with it without looking stupid [laughs]". Bev expresses a similar sentiment, saying:

I don't want to make a show of myself. I don't want to look ridiculous even though having said that it's an environment where you can be and do as you like. For me I'd rather be a bit more quiet about my presence. ... I don't want to look like a twat.

Hence, the felt sense of being out of place and having to manage this as a potential problem was a palpable aspect of our participants' engagement with psytrance.

"Getting it right" involves modifying their self-presentation and considering the specific context they were about to enter. In terms of the former, Bev explains that:

It's actually quite a good thing to present yourself as an older woman that looks good and not just good for her age but looks good. Looks like they know what's going on as almost like an example. Okay so you know you don't have to get your tits out or have your belly button pierced but you can still look fucking good in this environment whatever age you are.

Diane feels the same way, saying "I won't have my boobs and my bottom hanging out or... do you know what I mean? There is within reason obviously but for the most part I can just be whoever I want to be on that particular night". Such age/space appropriate dressing was couched in a positive light, for example, with Carol reporting with relief that "I don't feel I have to impress anybody". However, our participants were also communicating implicitly the pressure they felt as older women to present themselves in de-sexualised ways.

In terms of considering the specific context they were about to enter, getting their appearance right could be very complex. For Anita this involved understanding the difference between festivals and clubs such that "at festivals probably I do wear slightly ridiculous outfits that I wouldn't wear if I went to a club". The specific context is a consideration also for Diane who explains that "I can still quite happily wear the bright clothes and maybe something - a lot of other people say 'oh, you're a bit too old to be wearing that, but in a club-that social environment-it's more acceptable". Bev is also very aware of context but, 
unlike Anita and Diane, expresses more of a wish to remain incognito: "I will wear clothes that are appropriate to the event but I don't particularly want what I wear to say too much about me". Hence, our participants experience also pressure to mute the flamboyance of their self-expression.

All our participants also stress how dressing for comfort has become increasingly important. For example, Anita says "unlike the old days where I would be wearing ridiculous uncomfortable shoes just for the sake of fashion or appearance-absolutely shoes-it's comfort is number one". For Bev, it is straightforward: "I predominantly dress for comfort", as it is for Carol: "the main thing is to be comfortable, to have comfortable clothes". And Diane explains that:

I like to be very bright and colourful but I also like to be really comfortable because there's nothing worse being on the dancefloor and not being comfortable. And that's probably the older woman in me. You know I need to be comfortable and I dress for me really the way that makes me feel good and I'm not bothered if other people don't like it which you don't often find anyway.

Even so, Bev conveys with pleasure how she still gets called "a legend. You're an icon or whatever". She continues "of course it's all bollocks but it is sort of quite nice. And I've got other friends who are even more out there and glamorous and fabulous and old that you just sort of think 'yeah fucking bring it on, you know? You sad 25 year old, you know? Look at what you can be"'.

\section{SUB-THEME 3: SEXUAL HARASSMENT}

Despite our participants' awareness of having to manage the conspicuousness of their age, modifying their appearance according to context and dressing for comfort, three reported being sexually harassed. In Anita's experience "even when you're an older woman you're still preyed upon", and Diane reports that she "sometimes get chatted up by younger men and then I'll say to them, 'look, I am such-and-such an age' and they'll go, 'oh'. Some will run. Some will try their luck, you know ?" In a colourful passage, Bev describes her experience of being chatted-up by younger men on the scene:

Bizarrely but even that might be something to do with my age. I mean sometimes I just think, 'how fucked are you? Can you not tell that I'm, you know, twice your age?' And sometimes it really doesn't matter. Sometimes they go 'yeah of course I know you're old. You're still hot though' [laughter].

And Bev did not perceive this as necessarily a bad thing: "it amuses me more than anything. But yeah of course it's better for that. Well yeah, course it's quite nice". However, even though some of these experiences are narrated in a light-hearted manner, they include aspects of self-denigration in the implication that there is a time-space mismatch per se positioning an older woman in a sexualised space. 
Some participants report having to develop practical strategies to help them feel safe. For example, Anita says: "I always need to know where [name of husband] is because if I don't know where he is that can make me feel quite anxious so we'll usually agree that one of us will wear something that is noticeable". This is, at least in part, due to bad experiences, as she explains:

I've had a man come up to me and sort of touch my thigh which I considered inappropriate and you have to sort of say 'don't touch me' and I would point out, you know, 'I'm with my husband. Go away please.' If I was on my own, yeah, I wouldn't feel comfortable.

\section{THEME 2: OTHER-SPACE}

"Other-space" captures the way in which, despite having to manage the problems raised by their increased visibility, our participants leveraged the most enjoyment possible from the alternative environment provided by psytrance culture. Other-space is divided into four sub-themes: context, well-being space, well-being drugs, and well-being friends.

\section{SUB-THEME 1: CONTEXT}

The increased visibility experienced by our participants was mostly unwelcome and needed managing in order to enjoy their engagement in electronic dance music culture. In particular, they describe becoming more discerning about the places they would go. Anita says: "I'm quite selective now. I'll be thinking about who's going to be there, how big is it, what's the security like and then, importantly, what is the night about, what's the music going to be like?" She also underscores the skill in doing so: "we've got good at choosing the right ones". Similarly, Carol reports that "I like to go to events where I know I'm going to know people but also that are going to be large enough to know that there'll be lots of new people as well”. Moreover, Bev increasingly likes:

going to those places that you go to regularly where there would be new people but you're not going to an unknown. You know what to expect to a certain degree but you're pretty much guaranteed that certain types of things will or will not happen... having spent the last year or so being more selective.

\section{SUb-THEME 2: WeLL-BEING SPACE}

Becoming more discerning is related to leveraging as much enjoyment as possible from a particular event. The main enjoyment sought by participants was the sense of well-being that could be experienced within the other-space provided by psytrance. This is described using terms such as "shamanistic", "shutdown" and "reboot". It is Bev who makes a spiritual allusion, explaining that "it's almost shamanistic isn't it? Whatever it is and it's, you know, we are all in an environment where we're a different version of ourselves". However, Bev also draws on a technological concept saying that "it does change your hardwiring". Anita and 
Diane also use technological language. Anita says, "it's quite difficult to define but I still find that I get - what I get is a form of shutdown in terms of activity in my mind" and Diane reports that "reboot is the only way that I can put it because it does that for me. It helps me reboot. I get away from everything". Interestingly, all these allusions and metaphors convey how participants felt transformed through their engagement with the other-space provided by the psytrance experience.

Escapism is also very important, with Bev finding a sense of well-being through "an escape from every day" and Diane describing in more detail how "the escapism-it's just the whole package is the healing thing for me. So in itself that's the best bit [laughter] ...it was my adult time. It was me time and it was crucial to myself and to the children". Important also is the feeling of elation and of having fun, with Diane saying also that "it seems like it brings out my inner child ... just being silly, having fun, joking, making light of things" and that "I haven't let age decide when I should stop having fun". Carol reports how this sense of well-being could extend beyond the actual event in that "you feel elated. I mean you're very relaxed the next day and stimulated as well. You've got all sorts of new things to process. New people to think about". On the other hand, although Bev reports a similar experience of well-being in terms of "actively engaged hedonism ...thoughtful hedonism", she perceives a reduction in this with age such that "my euphoric moments are fewer and far between". However, although she ponders her limits, Bev offers a wry picture of the ultimate transformation that might be experienced in dance music other-space: "there must become a time where either things you want to go to just stop or one just stops. Maybe you just die on the dance floor".

Our participants were clear that this configuration of other-space was a place in which they could leave behind their everyday, domestic, and working lives. For example, Diane says "while I'm lost in the music I'm not thinking about bills or worries or stresses". However, as discussed in "(Non-)acceptance" above, as older women, our participants paradoxically tended to be situated by other clubbers in domestic and familial space. Hence, it is interesting to note that our participants, themselves, made pertinent the domestic sphere in various ways. Anita did this through contrasting the dance music other-space to her own domestic space, saying "I don't think I can recreate that feeling in my home". Others implicitly domesticated other-space in that for Bev a particular club "was like going home" and at events Diane feels "like I'm at home sometimes". Finally, perhaps most radically, Carol suggests that, given her huge enjoyment of electronic dance music, "they should be doing this for old people in old people's homes". Hence, the ways in which our participants are situated within, and their relationship between, electronic dance music other-space and domestic space appears complex and interweaving.

\section{SUB-THEME 3: WELL-BEING DRUGS}

Some participants made reference to the potential benefits of drugs to enhance their experience of well-being in EDM other-space. Bev, for example, reports that they could really help her to get the most out of an event explaining that "several hours and quite a bit 
of medication and then I do have euphoric times." Carol also views drugs as beneficial to the sense of well-being she gets from events saying "the drugs that I take now when I go out are much more of a social drug so you just feel like talking to people. You feel relaxed". On the other hand, for Anita, it is not necessary to use drugs because "your body will naturally want to move and that's even regardless of any chemical assistance".

Interestingly, Carol and Diane make a specific contrast between the drugs associated with EDM other-space and anti-social effects of alcohol. For example, Carol describes how:

we used to get drunk. I mean that was our way of sitting on our inhibitions but you're being sick or you're rushing off to the toilet because you feel woozy and you've got to check on your friend who's not appeared recently and check that she's not passed out somewhere. I mean it was not a social thing. It was just a way of shielding yourself from your inhibitions really. Just masking them whereas I think the MDMA removes them so they're not an issue.

Similarly, Diane says "it wasn't an atmosphere or a time that really appealed to me you know. The getting drunk and not remembering half the things and, you know, obvious fights breaking out and maybe people being rude to you".

\section{SUBTHEME 4: WeLL-BEING FRIENDS}

For our participants, the psytrance other-space was also of vital importance to their wellbeing through the opportunities it afforded them to make friends and to feel connected to a community of like-minded people. For example, Bev says "we established some good friends. I genuinely have friends in their 20s and 30s who I've met through this and I'm not just sort of like the token older person, you know? We have proper relationships." And Anita explains how "my circle of friends has expanded in terms of, you know, kindred spirits over the last five years." Carol even describes how it is the people who "make" an event: "[name of club] I find so scuzzy. It's absolutely disgusting. It just turns me ill. But the crowd-I've had the best night ever just by mixing with people who are so open and friendly." For Carol, this is important because "as you get older, particularly when you've retired as well, you become marginal." Moreover, Diane explains the benefits, at her age, of socialising:

You don't have to be dancing all the time. You're socialising. You're around people who are being very positive and haven't seen you for a while. They're very happy to see you and you're in a beautiful location and you're making new connections and reconnecting with old connections.

Socialising with friends was contrasted to a perceived pressure on younger people to secure a romantic relationship. Anita explains: "I think initially the force to go out- there was a lot of emphasis on meeting people, meeting partners, having relationship experiences." And being part of a social scene that provided stimulating connections was, in fact, viewed as increasingly important with age. This is expressed particularly eloquently by Carol: 
I came home and said, 'this is what they should be doing for old people in old people's homes, I've had more exercise, I've been more stimulated, I've met more people, and I just feel great. I feel energised. You know, I feel wonderful'. How long before the government have started to prescribe this to old people who are at home marginalised and don't know what to do with themselves? They bloody better had.

\section{Discussion}

The discussion will address the complex interplay between being and performing older woman in the context of EDM culture with a view to understanding how these experiences contribute to the lived identity of women of a certain age within a scene that is itself aging. It covers the two main themes emerging from the interview material, namely visibility and other-space.

As Judith Butler says, "identity is not static or essential, but performative" (1993: 95). Furthermore "performativity is a discursive act that enacts or produces the thing that it names" (Butler 1993: 13). Starting with the premise that performativity is a productive, generative agent, our research deals with the enactment of the category of older woman and considers how that particular marker of identity performs and is produced in the context of EDM culture. What is being enacted by older women in this context? How can the visual identities of our respondents be considered performative in club cultures? How does age itself perform and play out in the club space? And, if the very presence of older women in a club environment can be considered to be a discursive act, what further questions does this prompt about the presence of aging female bodies and the potential challenges they present to culture(s) in the wider sphere?

(In)visibility is central to most feminist studies of age and aging (e.g., Calasanti and Slevin 2006). As Woodward claims, the invisibility of older women is "a parable of generational ignorance" and Cobrin and Levine argue that, within scholarship, female aging continues to be "defined on a deficit model" (Woodward 1999: ix; Cobrin and Levine 2012: 2). In other words, getting older means moving to the margins of visibility in the labour market, visual market and socio-political market. Despite the ubiquity of the (in)visibility narrative that accompanies discourses of female aging, our research offers a different perspective. In the context of club culture, the figure of the older woman produces an interesting interplay between invisibility and hypervisibility. Specifically, we notice a disruption of the deficit model of aging where getting older equates to "cultural exile" and, instead, see a claiming of cultural space that resists normative values of what is appropriate behaviour for an older woman (Meagher 2014: 103).

By virtue of their age, our respondents occupy an unusual time-space constellation in the club context which has been traditionally seen as the preserve of the young. Being identified as older women makes them conspicuous and creates a type of "performance of incongruity" where the women's presence and the visual aesthetic they carry on and in their bodies, disrupt the expectations of others within the shared space (O'Grady 2009: 240). Reactions 
from other clubbers can be both positive and negative but the key point is that their visible presence alone is enough to produce comment, provoke reaction and, invariably, demand a response from the women themselves. These exchanges produce an immediate tension for the women as they navigate and manage the dynamic oscillation between invisibility and hypervisibility. Despite being very visible in the club due to the way age is performing as a marker of identity, the women talk of wanting to be inconspicuous so that they can enjoy themselves without interruption. While in the world of the everyday they might experience invisibility in negative terms, their visibility in the club scene can be a barrier to achieving the sense of "elsewhere", to use Pini's term (2001), or other-space they seek.

Hypervisibility, and the potential it affords, is, however, not lost on the women who find ways of harnessing it for their own ends. Being viewed as a person out of place produces a certain playfulness in the verbal exchanges that occur. What is, or what is not, age appropriate in this context becomes a site of playful resistance, or challenge, to entrenched cultural norms that operate in the world. The way they choose to present themselves in the club resonates with the work of artists such as Cindy Sherman and Martha Wilson who play with the "to-be-looked-at-ness" of female representation in order to subvert it (Mulvey 1975). The ways in which older women are associated with the domestic and the familial produces another instance of incongruity where the visual identity marker of having white hair, for instance, is at odds with being present in a sexualised space where predatory behaviour is not uncommon.

Despite claims that, in the rush of the early days at least, rave culture presented a largely de-sexualised terrain (Melechi 1993; Hemment 1997; Pini 1997), the testimony of the respondents suggest that sexual harassment is another instance of time-space mismatch where they are forced to negotiate their status as older women. It is interesting to note that although inclusive club cultures such as psytrance have a long established reputation of being safe spaces for women, the testimony of our respondents challenges this notion in that they describe being subject to overt sexualisation and objectification. While some of the women mention the positives of this and have developed playful ways to address it, the club context presents a problem for them in the same way as it does for younger women. Moreover, it is possibly an area in which older women are particularly vulnerable as there may be the assumption that they should be "grateful" for sexual advances, unsolicited or not, due to their age. More positively, and perhaps controversially, is that these older women consider themselves to be sexual beings and are responded to as such by often much younger men.

In order to navigate the space safely, a number of tactical decisions are taken and practical strategies are adopted to ensure their access to and participation in the night is managed effectively. The strategies they adopt are well rehearsed and practised. In Schechner's framing this is "twice behaved behaviours" (1985). This indicates a maturity they bring to their engagement, even when their enjoyment might be judged from a more conventional position as inappropriate or even illegal. Their attitude and approach to recreational 
drug use, for example, is particularly measured. The risks and the pleasures are carefully considered and thought through based on experience. This comes across perhaps most clearly in the way the women talk about how they craft their appearance, a process that is laced with complex considerations linked to identity, sexuality, safety, pleasure, comfort and appropriateness. As older women who claim their place within a culture that is associated with youth, the visual representation they adopt could be considered as quiet subversion that presents a challenge to normative assumptions of age and gender. However, at times this quiet subversion threatens to get lost in the process of labelling individuals as "rave mum" or "granny" which tames their challenge by implicating conventional familial, ageist and domestic frames. Despite the attempts of others to consign older women to the domestic space, it is the quest for other-space and what that affords which fuels their participation in the scene.

The concept of other-space demonstrates the way in which clubs and festivals provide the women with an opportunity to access alternative versions of themselves. Framed in various ways, they all talk of the types of transformation they feel are achieved through actively engaged hedonism, namely escape, ritual, healing and well-being. Here the language they use points towards an instrumental approach to clubbing that leads to shutdown, reboot and recalibration. To achieve these states, the women consider set and setting to be key and dedicate a great deal of thought to the elements that will facilitate their journey into otherspace. This includes the use of drugs as a type of Foucauldian technology of the self(Martin, Gutman and Hutton 1988). They are hyper-aware of the conditions necessary to access a state of transcendence and can articulate the barriers and obstacles equally well. The barriers are associated with unwanted advances, sensing they are out of place or among the wrong crowd, feeling vulnerable - situations that create unsettling or destabilising sensations.

The sense of well-being derived from participation in club culture is located predominantly in friendship networks. For older people who often find themselves in an increasingly marginalised position in society, the opportunity for intergenerational recreation, let alone latent hedonism, is rare. This is perhaps one of the biggest challenges to societal norms our research demonstrates. Intergenerational friendships fulfil many functions associated with affection and satisfaction. They provide companionship, help, intimacy, alliance, self-validation and emotional security (Mendelson and Aboud 1999). Having fun together is important to friendships more widely (Hartup and Stevens 1999; Way 2013) and can contribute significantly to a rich network of interpersonal exchanges that lead to growth, shared meaning-making and mutual understanding (LaGuardia 2008). Having the opportunity to establish and grow intergenerational friendship networks through conscious hedonism plays an important part in the women's continued participation and presents further challenge to the more conventional assumptions of what fun might look like to a woman in her 50 s or 60 s. 


\section{CONCLUSION}

The experience of older women who participate in EDM culture is noticeably absent from extant scholarship despite the scene itself entering its fourth decade. The terms scarcity, deficit and invisibility accompany scholarly considerations of female aging, not least in relation to clubbing practices. Our research offers a critique of the narrative of invisibility that accompanies much of the existing work on the experiences of older women and foregrounds the tactical engagement of this particular cohort as a form of quiet subversion. In the club context older women find themselves being conspicuous by virtue of their age. Their presence on the dance floor presents a challenge to what society considers "appropriate" behaviour for women beyond a certain age and, as such, can be framed as a process of resistance, however reluctantly adopted. Our research illuminates the challenges such women face, the various reactions they prompt from other clubbers and the strategic approaches they take to deal with these. The ways in which older women resist and defy normative configurations of age/gender subjectivities, raises interesting questions about female aging in contexts beyond the club space.

Our research challenges the view that particular behaviours have a shelf life and that being an older woman excludes one from certain activities, particularly those that might be considered hedonistic, deviant or illegal. Our research suggests that older women are not participating in club culture despite of their age. In most instances they are participating because of their age. Each of our respondents came to the psytrance scene relatively late in life and it offers them an experience of well-being and intergenerational social connectedness that would be difficult for them to access in other contexts. In fact, their age and experience enabled them to lever maximum enjoyment from occupying other-space via actively engaged hedonism.

\section{ACKNOWLEDGEMENTS}

Heartfelt thanks to the women who shared their experiences and stories with us so candidly and graciously. Thanks also to Jade Bannister for assisting us search for relevant literature in the early stages of this project.

\section{NOTES}

1 We use the term "older woman" throughout this article but deliberately resist defining individuals in this category by chronological age. We acknowledge that the term is relative and dependant on context. For the purposes of this study, we were interested in speaking to women who consider themselves to be older within the context of the psytrance scene. This placed our informants within an age bracket of 52-67. In other scenes, this may vary. With this caveat in mind, our investigation is interested in the experience of women who have moved beyond 
child bearing age and who are experiencing what might be best described as a transitional phase of life which may or may not be accompanied by symptoms of the menopause.

\section{REFERENCES}

Bennett, Andy. 1999. "Subcultures or Neo-Tribes? Rethinking the Relationship Between Youth, Style and Musical Taste”. Sociology 33(3): 599-617.

Braun, Virginia and Victoria Clarke. 2006. "Using Thematic Analysis in Psychology". Qualitative Research in Psychology 3(2): 77-101. <http://dx.doi.org/10.1191/1478088706qp063oa>.

Butler, Judith. 1993. Bodies that Matter. London: Routledge.

Calasanti Toni M. and Kathleen F. Slevin. 2006. Age Matters: Realigning Feminist Thinking. London: Routledge.

Chatterton, Paul and Robert Hollands. 2003. Urban Nightscapes: Youth Cultures, Pleasure Spaces and Corporate Power. London: Routledge.

Cobrin, Pamela and Debra Levine. 2012. "Introduction." Women and Performance: A Journal of Feminist Theory. Special Issue Aging 22(1): 1-7. < https://dx.doi.org/10.1080/074077

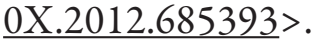

D'Andrea, Anthony. 2010. “The Decline of Electronic Dance Scenes”. In The Local Scenes and Global Cultures of Psytrance, ed. Graham St John, 40-54. New York: Routledge.

Davies, Paul. 2013. Nightclubs - UK - May 2013. London: Mintel Academic. <http://academic.mintel.com/display/638091/>, (accessed 2 August 2018).

Dixons Carphone. 2017. "Stay at Home Brits". 5 July. <https://www.dixonscarphone.com/en/ news-and-media/press-releases/year/2017/stay-at-home-brits $>$, (accessed 17 July 2018).

Farrugia, Rebekah. 2004. "Sisterdjs in the House: Electronic/Dance Music and Women-Centered Spaces on the Net”. Women's Studies in Communication 27(2): 236-62. $<$ http://dx.doi.org/10.1080/07491409.2004.10162474>.

-_- 2012. Beyond the Dance Floor: Female DJs, Technology and Electronic Dance Music Culture. Bristol, UK: Intellect.

Farrugia, Rebeka and Magdalena Olszanowski. 2017. "Introduction to Women and Electronic Dance Music Culture”. Dancecult: Journal of Electronic Dance Music Culture 9(1): 1-8. <http://dx.doi.org/10.12801/1947-5403.2017.09.01.00>.

Gadir, Tami. 2016. "Resistance or Reiteration: Rethinking Gender in DJ Cultures”. Contemporary Music Review 35(1): 115-29. < http://dx.doi.org/10.1080/07494467.2016.1176767>.

_- - 2017. "Forty-Seven DJs, Four Women: Meritocracy, Talent, and Postfeminist Politics". Dancecult: Journal of Electronic Dance Music Culture 9 (1): 50-72. <http://dx.doi.org/10.12801/1947-5403.2017.09.01.03>.

Gomersall, Tim and Anna Madill. 2015. "Chronotope Disruption as a Sensitizing Concept for Understanding Chronic Illness Narratives”. Health Psychology 34(4): 407-16. < http://dx.doi.org/10.1037/hea0000151>.

Greer, Germaine. 2018. The Change: Women, Ageing and the Menopause. London: Bloomsbury Publishing. 
Gregory, Julie. 2009. “Too Young to Drink, Too Old to Dance: The Influences of Age and Gender on (Non) Rave Participation". Dancecult: Journal of Electronic Dance Music Culture 1(1): 65-80. $<$ http://dx.doi.org/10.12801/1947-5403.2009.01.01.04 >.

Hancock, Maren. 2017. "Lick My Legacy: Are Women-Identified Spaces Still Needed to Nurture Women-Identified DJs?” Dancecult: Journal of Electronic Dance Music Culture 9(1): 73-89. <https://dx.doi.org/10.12801/1947-5403.2017.09.01.04 >.

Hartup, Willard and Nan Stevens. 1999. "Friendships and Adaptation Across the Life Span". Current Directions in Psychological Science 8 (3):76-9. $<$ https://dx.doi.org/10.1111/1467-8721.00018>.

Henderson, Sheila. 1993. "Luvdup and De-elited: Responses to Drug Use in the Second Decade". In AIDS: Facing the Second Decade, ed. Peter Aggleton, Peter Davies and Graham Hart, 119-30. London: Falmer.

Hemment, Drew. 1997. "E is for Ekstasis”. New Formations 31: 23-38. London: Lawrence and Wishart.

Hinchliff, Sharron. 2001. "The Meaning of Ecstasy Use and Clubbing to Women in the Late 1990s”. International Journal of Drug Policy 12(5-6): 455-468. <https://dx.doi.org/10.1016/S0955-3959(01)00113-X $>$.

Hutton, Fiona. 2006. Risky Pleasures? Club Cultures and Feminine Identities. Aldershot: Ashgate. Jordan, Tim. 1995. "Collective Bodies: Raving and the Politics of Gilles Deleuze and Felix Guattari". Body and Society 1(1): 125-44. <https://dx.doi.org/10.1177/1357034X95001001008>.

La Guardia, J. G. 2008. “On the Role of Psychological Needs in Healthy Gunctioning: Integrating a Self-determination Theory Perspective with Traditional Relationship Theories”. In The Self and Social Relationships, ed. Joanne V. Wood, Abraham Tesser and John G. Holmes, 27-48. Hove, East Sussex: Psychology Press.

Laz, Cheryl. 2003. "Age Embodied”. Journal of Aging Studies 17(4): 503-19.

Lindop, Robin. 2010. "Re-evaluating Musical Genre in UK Psytrance”. In The Local Scenes and Global Cultures of Psytrance, ed. Graham St John, 114-30. New York: Routledge.

Madill, Anna. 2008. "Realism". In The SAGE Encyclopedia of Qualitative Research Methods, ed. Lisa M. Given, 731-35. London: Sage.

Madill, Anna. 2012. “Interviews and Interviewing Techniques”. In American Psychological Association Handbook of Research Methods in Psychology, ed. Harris Cooper, Paul Camic, Debra Long, A.T. Panter, David Rindskopf and Kenneth Sher, 249-75. Washington, DC: American Psychological Association.

Martin, Luther H., Huck Gutman and Patrick H. Hutton (ed.). 1988. Technologies of the Self: A Seminar with Michel Foucault Amherst, Mass.: University of Massachusetts Press.

McGrath, Rebecca. 2016. Nightclubs - UK - May 2016. London: Mintel Academic. $<$ http://reports.mintel.com/display/772718/>, (accessed $2^{\text {nd }}$ August 2018).

McRobbie, Angela. 1993. "Shut Up and Dance: Youth Culture and Changing Modes of Femininity”. Youth 1(2): 13-31. <https://dx.doi.org/10.1177/110330889300100202>.

McRobbie, Angela. 1994. Postmodernism and Popular Culture. New York: Routledge.

Meagher, Michelle. 2004 "Against the Invisiblity of Old Age: Cindy Sherman, Suzy Lake, and Martha Wilson". Feminist Studies 40(1): 101-43. 
Measham, Fiona. 2002. “Doing Gender'-'Doing Drugs': Conceptualizing the Gendering of Drugs Cultures". Contemporary Drug Problems 29(2): 335-73. <https://dx.doi.org/10.1177/009145090202900206>.

Melechi, Antonio. 1993. "The Ecstasy of Disappearance”. In Rave Off: Politics and Deviance in Contemporary Youth Culture ed. Steve Redhead, 29-40. Aldershot: Avebury.

Mendelson, Morton J. and Frances E. Aboud. 1999. "Measuring Friendship Quality in Late Adolescents and Young Adults: McGill Friendship Questionnaires”. Canadian Journal of Behavioural Science/Revue canadienne des Sciences du comportement, 31(2): 130-32.

Morris, Hugh. 2014. "How Old is Too Old to go Clubbing?" The Telegraph. 17 $7^{\text {th }}$ August. $<$ https://www.telegraph.co.uk/men/the-filter/11029196/How-old-is-too-old-to-go-clubbing.html $>$, (accessed 2 August 2018).

Morson, Gary. 1994. Narrative and Freedom: The Shadows of Time. New Haven, CT: Yale University Press.

Mulvey, Laura. 1975. "Visual Pleasure and Narrative Cinema". Screen 16(3): 4-5. $<$ https://dx.doi.org/10.1093/screen/16.3.4 >

O’Grady, Alice. 2009. "Underground Club Spaces and Interactive Performance”. Ph.D. Dissertation (Performance Studies), University of Leeds.

Olszanowski, Magdalena. 2012. "What to Ask Women Composers: Feminist Fieldwork in

Electronic Dance Music". Dancecult: Journal of Electronic Dance Music Culture 4(2): 3-26. $<$ http://dx.doi.org/10.12801/1947-5403.2012.04.02.01>.

Pini, Maria. 1997. "Cyborgs, Nomads and the Raving Feminine", in Dance in the City, ed. Helen Thomas. 111-29, London, Routledge.

Pini, Maria. 2001. Club Cultures and Female Subjectivity: The Move from Home to House. Basingstoke: Palgrave.

Redhead, Steve. (ed.). 1993. Rave Off: Politics and Deviance in Contemporary Youth Culture, Aldershot, Avebury.

Rietveld, Hillegonda. 1993. "Living the Dream". In Rave Off: Politics and Deviance in Contemporary Youth Culture, ed. Steve Redhead, 42-78. Avebury Press: Aldershot.

Rosa, Reitsamer. 2012. "Female Pressure: A Translocal Feminist Youth-oriented Cultural Network". Continuum 26(3): 399-408. <https://dx.doi.org/10.1080/10304312.2012.665837>.

Rodgers, Tara. 2010. Pink Noises: Women on Electronic Music and Sound. Durham, NC:

Duke University Press.

- - - 2012. "Towards a Feminist Historiography of Electronic Music". In The Sound Studies Reader, ed. Johnathan Sterne, 475-490 London: Routledge.

Schechner, Richard. 1985. Between Theater and Anthropology. Philadelphia: University of Pennsylvania Press.

St John, Graham. (ed.). 2010. The Local Scenes and Global Cultures of Psytrance. New York: Routledge.

- - - 2012. Global Tribe: Technology, Spirituality and Psytrance. Bristol: Equinox.

Taylor, Jodie. 2010. "Queer Temporalities and the Significance of 'Music Scene' Participation in the Social Identities of Middle-aged Queers”. Sociology 44(5): 893-907.

Thornton, Sarah. 1995. Club Cultures: Music, Media and Subcultural Capital. Cambridge: Polity Press. 
O'Grady and Madill | Being and Performing “Older” Woman in Electronic Dance Movement Culture 29

Way, Niobe. 2013. "Boys' Friendships During Adolescence: Intimacy, Desire, and Loss”. Journal of Research on Adolescence 23(2): 201-13. < https://dx.doi.org/10.1111/jora.12047>. West, Candace and Don H. Zimmerman. 1987. "Doing Gender". Gender and Society 1(2), 125-51. Woodward, Kathleen (ed.). 1999. Figuring Age: Women, Bodies, Generations. Bloomington: Indiana Press 